\title{
Improved NARP-HPLC method for separating triglycerides of palm olein and its solid fractions obtained at low temperature storage
}

\begin{abstract}
Non-aqueous reversed-phase high-performance liquid chromatography (NARP-HPLC) with refractive index (RI) detection is described and used for palm olein and its fractions obtained at $12.5{ }^{\circ} \mathrm{C}$ for $12 \mathrm{i} 24 \mathrm{~h}$. The calculation formula for fatty acid methyl esters (FAMEs) and carbon number $(\mathrm{CN})$ from the data obtained by NARP-HPLC is described and correction factors for all carbon numbers and fatty acids are tabulated. The results were compared with those obtained from FAMEs analysed on 10\% SP 2330 Supelco packed column gas-liquid chromatography (GLC) and CN analysed on 3\% OV-1 Supelco packed column GLC. The results were found to agree well for $\mathrm{C} 48, \mathrm{C} 50, \mathrm{C} 52, \mathrm{C} 16: 0, \mathrm{C} 18: 0$ and C18:1 (correction factor å 1.0); however, a slight variation was observed for components C54, C14:0 and C18:2 (correction factor $1.0 \pm 0.37$ ).
\end{abstract}

Keyword: Non-aqueous reversed-phase high-performance liquid chromatography (NARPHPLC); Refractive index (RI); Palm olein 